\title{
An empirical survey to investigate quality of men's clothing market using QFD method
}

\author{
Samira Golshan $^{\mathrm{a}^{*}}$, Hassan Javanshir ${ }^{\mathrm{b}}$ and Abosaied Rashidi ${ }^{\mathrm{a}}$
}

${ }^{a}$ Department of Texture Industry, Science \& Research Branch, Islamic Azad University (IAU),Tehran, Iran

${ }^{b}$ Department of Industrial Engineering, Islamic Azad University, South Tehran Branch, Iran

\begin{tabular}{l}
\hline A R T I C L E I N F O \\
\hline Article history: \\
Received December 18, 2011 \\
Received in Revised form \\
February, 28, 2012 \\
Accepted 16 April 2012 \\
Available online \\
April 18 2012 \\
\hline Keywords: \\
QFD \\
Customer satisfaction \\
Quality control \\
House of quality
\end{tabular}

\section{Introduction}

Clothing along with food and housing are three basic requirements for human survival and life. When there is a boom in clothing industry, we could expect some advances on quality of people's lives. A good quality product can meet people's needs, which include durability, beauty, safety, etc. (Chan et al., 2009). Quality is a concept, which implies on priority of a particular good or services and it plays an important role on increasing sales of clothing. Quality function deployment (QFD) is one of the most important techniques for reaching the necessary quality through house of quality technique. QFD is believed to be one of the most important techniques to reach customers' expectations (Chuter, 2002). Akao is believed to be one of the first people who focused on quality (Xie et al., 2001; Chan \& Wu, 2003; Seva et al., 2011). Yueh (1996) used QFD to improve quality of clothing by gathering different important factors influencing the quality of products. They considered new customer's style and changed their advertisements techniques as well as packaging style to increase sales. In other

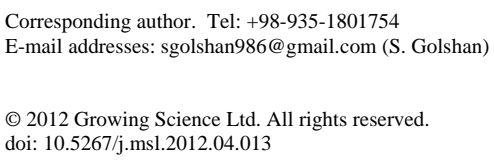


research, May-Plumlee (1996) used QFD to increase flexibility of clothing for workers. Huang and Tan (2007) implemented QFD to apparel design in Taiwan by considering different products' characteristics such as fashion, quality of clothing materials and cutting, price, etc. Chan et al. (2002) applied QFD in the clothing manufacturing sector in an empirical study on improving a distancelearning program in Hong Kong. Chan et al. (2009) used QFD to develop a training course for clothing merchandisers. Huang and Tan (2007) used applications of QFD to apparel design in Taiwan.

The proposed study of this paper uses QFD to detect important items influencing clothing industry in Iran. The focus of this paper is on men's shirt and it uses a questionnaire and interview to find necessary information associated with design and customers' perspectives. The organization of this paper first presents details of our survey in section 2 and the results are given in section 3 . The paper ends with concluding remarks to summarize the contribution of the paper.

\section{The proposed study}

\subsection{Quality function deployment}

The proposed model of this paper uses the following items to investigate the necessary requirements (Kim, 1998),

\subsubsection{Who (Customer perception)}

We first gather all the necessary information associated with customer's expectations. Note that customer will say the last word and they are the primary source of income. Therefore, we need to carefully determine demand, precisely. The proposed study of this paper focuses men who are 15 to 45 years old living in Yazd/Iran. The brand we do the investigation sells the products in three shopping centers located in this city. We have distributed 100 questionnaires and collected 65 properly filled ones. During the survey, we have provided accompanied surveyed people just to make sure they could fully understand the concept of the survey along with the objectives. In case there was any question, we did our best to explain the survey making sure that the responses are consistent with what we expect from them.

\subsubsection{What (Customer needs)}

In this section, we look for customer expectations in terms of what they expect from a men's shirt. The necessary quality characteristics are determined by interview and adjusting a questionnaire.

\subsubsection{Who-What}

In this stage of our survey, we determine the relationship between customer expectation and design requirements and form the necessary matrix, which shows the relationship among different components with the necessary weights.

\subsubsection{Now}

In this stage, we make an assessment on present states of customer satisfaction in terms of quantitative value. The assessments must have been carefully performed using the feedback received from 65 customers who participated in our survey.

\subsubsection{How}

In this stage, we determine how to make a clear response to customer in terms of quantitative figures based on the required technical knowledge and expert people who have enough experience and they are somehow associated with customers. 


\subsubsection{How to What}

In the section, we determine how to address all necessary concerns.

\subsubsection{How on How}

All technical relationships are determined in this section based on the relative weights given in the previous sections.

\subsection{Relative importance of technical characteristics}

One of the most important parameters in house of quality is to determine the weight of each component, which can be computed as follows,

$\mathrm{T}_{\mathrm{i}}=\sum_{\mathrm{j}=1}^{\mathrm{K}_{\mathrm{i}}}\left(\mathrm{D}_{\mathrm{j}} \cdot \mathrm{R}_{\mathrm{ji}}\right), \quad(\mathrm{i}=1,2, \ldots, \mathrm{n})$

where $D_{j}$ is the relative importance of customer expectations based on $i^{\text {th }}$ technical factor, $R_{i j}$ is the number associated with technical characteristic $i$ with customer expectation $j, T_{i}$ is the importance of technical item $i, K_{i}$ is number of customer's expectations associated with technical characteristics $i$ and $n$ is the number of technical characteristics.

\subsection{The relative importance of technical characteristics}

Once we have determined the pure weight of technical characteristics, we need to prioritize them based on different methods. In order to reach desirable an precise results, we need to look into what the other competitors have considered for products (Karsak, 2004; Huang \& Tan, 2007). In this paper, since we analyze the products based on customers we use the following to calculate the relative importance,

$$
P_{i}=T_{i} \cdot \sum_{j=1}^{K_{i}}\left(d_{j} \cdot w_{j}\right),(i=1,2, \ldots, n)
$$

where $T_{i}$ is the pure rate of importance for technical attribute $i, d_{i}$ is the difference between the point given to the particular considered product and the highest point assigned to other products in terms of $j^{\text {th }}$ customer's preference, $w_{j}$ is the weight of $j^{\text {th }}$ customer's preference, $P_{i}$ is the final preference of the $i^{\text {th }}$ technical characteristic, $K_{i}$ is the number of customer's expectations associated with technical characteristic $i$ and $n$ is the number of technical characteristics. The relative weight of $j^{\text {th }}$ customer is also calculated as follows,

$$
w_{j}=\frac{D_{j}}{\sum_{j=1}^{K_{i}} D_{j}}, \quad\left(j=1,2, \ldots, K_{i}\right)
$$

\section{The results}

In this section, we present details of the implementation of the proposed model of this paper based on the criteria defied in Table 1. Also, Fig. 1 shows details of our investigation through house of quality. 
Table 1

Different characteristics and their weights

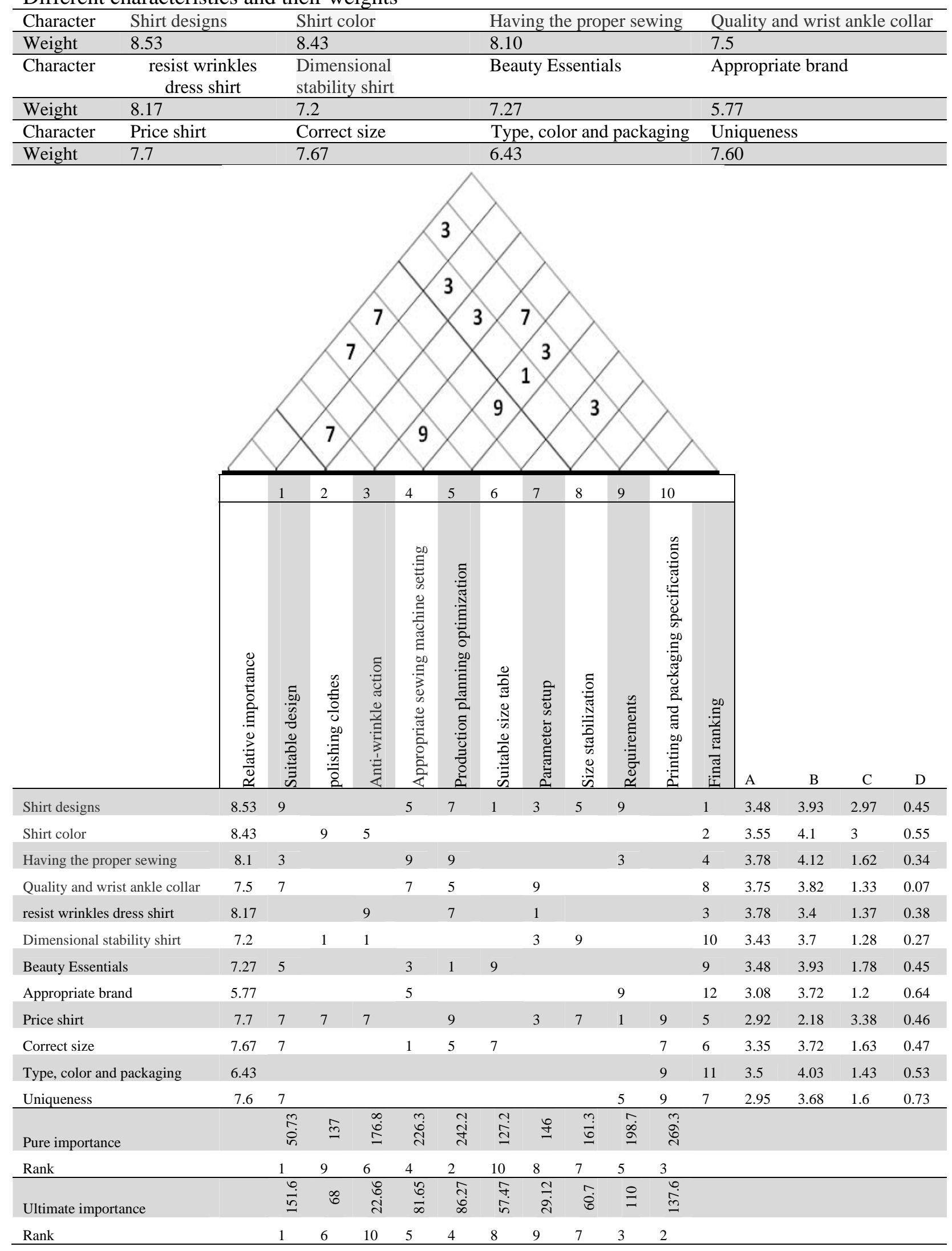

Fig. 1. House of quality for the proposed study 
Based on the results shown in Fig. 1 we can observe that the suitable design, printing and packaging specifications, necessary requirements, optimization of production planning and appropriate sewing machine setting are the most important characteristics. Fig. 2 shows details of our findings for the proposed study of this paper.

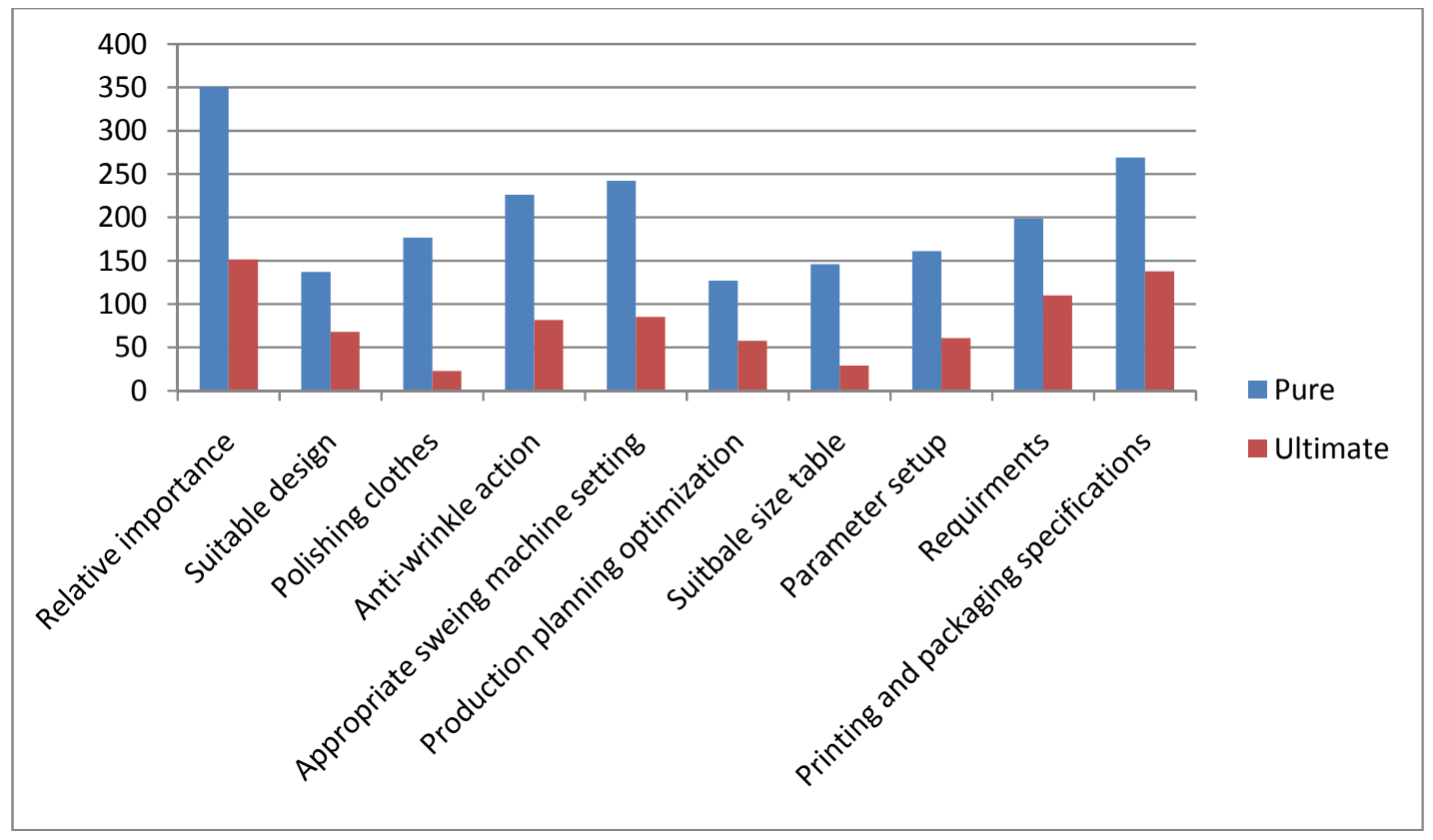

Fig. 2. The relative importance of different characteristics in terms of Pure and ultimate

\section{Conclusion}

In this paper, we have presented an empirical study to measure the impact of different characteristics on men's clothing products. The proposed study of this paper has gathered different characteristics influencing customer's intention on purchasing men's clothing and using QFD method provided the most important items. Based on the results of our survey, suitable design, printing and packaging specifications, necessary requirements, optimization of production planning and appropriate sewing machine setting are the most important characteristics influencing the purchase of a clothing products. Based on the results of this survey, we can conclude that increasing market sales in clothing and textile industry needs a comprehensive method to look for all-important items from customer's life style to optimization of production planning.

\section{Acknowledgment}

The authors would like to thank the people who participated in our survey. We are also grateful for the insights given by the anonymous referees on earlier version of this paper.

\section{References}

Chan, K., Chan, S.F., \& Chan, C. (2002). Applying QFD in the clothing manufacturing sector: A case study on improving a distance-learning program in Hong Kong. Managerial Auditing Journal, 17(1/2), 89-91.

Chuter, J. (2002). Quality management in the Clothing and Textile Industries. The Textile Institute, UK, ISBN: 1870372484. 
Chan, C.Y.P., Taylor, G., \& Ip, W.C. (2009), Applying QFD to develop a training course for clothing merchandisers. The TQM Journal, 21(1), $34-45$.

Chan, L.K., \& Wu, M.L. (2003). Prioritizing the Technical Measures in QFD, Quality Engineering, 10(3), 467-479.

Karsak, E. (2004). Fuzzy multiple objective programming framework to prioritize design requirements in quality function deployment. Computers and Industrial Engineering, 47(2-3), 149-163.

Kim, K.J. (1998), Determining optimal design characteristic levels in QFD. Quality Engineering, 10(2), 295-307.

Huang, Y.Y., \& Tan, B. (2007). Applications of quality function deployment to apparel design in Taiwan. Journal of Fashion Marketing and Management, 11(2), 215 - 237.

May-Plumlee, T. (1996). Application of TQM strategies to design of functional apparel: A case study. ITAA proceedings of the 1997 national meeting , 99.

Seva, R.R., Gosiaco, K.G.T., Santos, M.C.E.D., \& Pangilinan, D.M.L. (2011). Product design enhancement using apparent usability and affective quality. Applied Ergonomics, 42(3), 511-517.

Xie, M., Goh, T.N., \& Wang, H. (2001), A study of the sensitivity of customer voice in QFD analysis. International Journal of Industrial Engineering Application and Practices, 5(4), 301307.

Yueh,Y. (1996). Development a Total Quality Assurance System of an OBM Apparel Company. Proceedings of the 4th Asian Textile Conference. 